\title{
Walt Whitman en Hispanoamérica
}

F STUDIAR a Walt Whitman en la poesía hispanoamericana, es como buscar las huellas de un fantasma que se puede sentir en todas partes y ver en ninguna. Toda clase de críticos citan sus versos con dudosa exactitud; poetas de las más variadas tendencias se han inspirado en su mensaje y le han dedicado encomiásticos sonetos, o bien han repetido sus propias palabras en una especie de cándida renunciación.

Sin embargo, cuando tratamos de reunir una bibliografía sobre este problema literario y buscamos los ensayos de interpretación y las traducciones, escasamente se encuentra material que valga la pena. Parece que la mayoría de quienes se han referido a Whitman en Hispanoamérica le conocían indirectamente o de un modo superficial, y nunca lo suficientemente bien para traducirlo por completo o para intentar una interpretación seria de su obra.

Hay excepciones, y basándose en ellas sería posible escribir un estudio de bastante interés. En las presentes notas deseo presentar una breve selección de un material ya extenso, con el objeto de dar al lector una idea general del papel desempeñado por Whitman en el desarrollo de la poesía hispanoamericana. ${ }^{1}$

Estudiada nuestra poesía desde el punto de vista de la influencia de Whitman sobre sus más grandes figuras, es necesario distinguir tres momentos:

1) El período Modernista, en el cual el nombre de Whitman es introducido en Hispanoamérica. Aparece el famoso artículo de Martí escrito con ocasión de la visita que hiciera Whitman a Nueva York cuando murió Lincoln. ${ }^{2}$ Dario dedica un soneto a Walt Whitman, que aparece en $\mathrm{Azul} \ldots{ }^{3}$ Amado Nervo traduce algunos de sus poe- 
mas. El lenguaje bíblico del poeta norteamericano tiene una influencia devastadora sobre José Santos Chocano. Armando Vasseur traduce a Whitman in extenso. ${ }^{4}$

2) El Vanguardismo de postguerra, resultante de la revolución literaria francesa que había cortado todo vínculo con la tradición académica, relegó a Whitman a un plano secundario. Los nombres de Lautreamont, Rimbaud, Apollinaire, le reemplazan momentáneamente.

La democracia de un hombre nuevo que vive en su mundo no interesa a estos poetas que salen de una tragedia donde todos los mitos de la civilización parecieron experimentar un miserable fracaso. A1gunos, siguiendo de cerca a sus maestros franceses, se hunden en el turbulento marasmo de la subconsciencia. Se hacen dadaístas imitando a Tzara, Picabia; surrealistas a la Breton, creacionistas a la Huidobro. La mayor parte de ellos perece en una repulsiva y estéril estagnación. Unos pocos, los escogidos, se salvan y luchando peligrosa y apasionadamente contra el odio de los rezagados que ya trataban de aferrarse a cualquier cosa, aun al fascismo, para evitar su inevitable fin, avanzan hacia la aurora de una nueva poesía que se alza desde el fondo de la desesperación al orden constructivo de una revolución en marcha, que establece nuevamente la supremacía de Walt Whitman. A este período de transición pertenecen Pablo Neruda ${ }^{5}$ y Pablo de Rokha, a mi juicio, las dos figuras más importantes de la poesía hispanoamericana de hoy. Con ellos, por encima de un surrealismo que naufraga, surgen los nombres de César Vallejo el mártir peruano, Sabat Ercasty, ${ }^{6}$ Leopoldo Lugones, Martínez Estrada, ${ }^{7}$ Luis Franco, Parra del Riego, Carrera Andrade y otros.

3) Es un momento que pertenece a la generación más joven; a los poetas que empezaron a cantar cuando el corazón de España era devorado por los fascistas. Cantan con un acento civil, con un amor al hombre y a la democracia que viene directamente del autor de Song to Myself; hablan de las cosas que el hombre ha creado: ciudades, libros, música, máquinas. Por encima de todo, cantan el antiguo himno del amor a la tierra. Celebran las cosas que el hombre hace cuando es libre y feliz. Acerbamente denuncian la conspiración fascista. Conminan al pueblo a defenderse y a salvar su patrimonio. Cuando la guerra civil estalló en España muchos de ellos se enlistaron como voluntarios partiendo de las costas de México, Chile, Perú y otras 
tierras, para luchar por la libertad. El nombre del viejo profeta yanqui aparece numerosas veces en sus versos; le imitan en algunos casos sin gran maestría, pero siempre con sincera veneración. ${ }^{8}$ Saben que Whitman no es tan sólo el poeta de unos pocos años de democracia en los Estados Unidos; presienten que él está cantando una nueva era, una democracia sin contradicciones, una democracia que libertará al hombre de toda esclavitud. No podemos mencionar nombres por ahora, ya que no sabemos todavía cuántos de ellos van a sobrevivir.

Entre otras historias con que los poetas modernistas y sus críticos han conseguido entretener al público, está la de su estrecha afinidad con Whitman. Todas las historias de la literatura hispanoamericana señalan el hecho de que Whitman fué dado a conocer entre nosotros por el movimiento modernista. Ya hemos dicho que, en nuestra opinión, el "público" de Hispanoamérica no vino a saber del autor de Leaves of Grass hasta que Vasseur publicó su traducción, hace más o menos treinta años.

Si fuéramos a creerles a los críticos, resultaría que Darío y sus discípulos conocían a Whitman lo suficientemente bien como para estar influídos profundamente por su poesía y convertirse en verdaderos intérpretes de su mensaje. No es mi intención negar esta influencia, pero sí discutir la naturaleza que ella asumió. ¿Fueron los modernistas determinados por una profunda comprensión del mensaje de Whitman y por el irresistible deseo de continuar la batalla que él había iniciado? ¿Eran sinceros y en realidad poseían la grandeza de Whitman? ¿O acaso oían tan sólo el ruido de la corriente, no se daban cuenta de su poder ni de su sentido y vivieron repitiendo sones que no sentían ni podían comprender?

Es evidente que Darío, al menos, estaba familiarizado con la obra de Whitman cuando escribió su Autobiografía. ${ }^{9}$ De su admiración por el poeta norteamericano hay pruebas numerosas. En Prosas profanas ${ }^{10}$ afirma:

Si hay poesía en nuestra América ella está en las cosas viejas, en Palenke y Utatlán, en el indio legendario y en el indio sensual y fino, y en el gran Moctezuma de la silla de oro. Lo demás es tuyo, demócrata Walt Whitman.

Fué en un artículo, sin embargo, publicado en el periódico $L a$ Epoca de Santiago de Chile el 16 de noviembre de 1888 y recogido 
por Raúl Silva Castro, ${ }^{11}$ donde Darío expresó más ardientemente su fe en el gran maestro:

Sobre todos los sombríos pensadores desfallecientes, en medio de las tinieblas filosóficas antiguas y modernas, miro augusta y sacerdotalmente profética la figura de un anciano que todavía vive, que ha aparecido en las regiones del porvenir y de la libertad y cuya voz empieza a resonar por todas partes porque es él hoy el primer poeta del mundo.

Torres-Rioseco, en su libro sobre Darío, comenta también este punto:

Además de sus lecturas francesas trataba de interpretar a Walt Whitman en inglés y, a pesar de que conocía bastante mal este idioma; sabía penetrar con singular talento la esencia de los poemas del poeta de Camden. Desde entonces tuvo una exagerada admiración por la obra de Whitman... ${ }^{12}$

Sin embargo, en la página 193 del mismo libro Torres-Rioseco afirma que la Oda a Mitre empieza con las palabras: "Oh, captain, oh, my captain! - clamaba Whitman ...", lo cual, continúa Torres, muestra que Darío estaba citando a Whitman de memoria, ya que el verso de Whitman textualmente dice: "Oh captain, my captain ..."

Este hecho y la manera en que Dario habla siempre de Whitman, induce a pensar que su conocimiento del poeta yanqui era superficial y su admiración basada solamente en motivos sentimentales. Darío y sus discípulos mencionaban a Whitman a menudo; ninguno de ellos, no obstante, intentó jamás la traducción completa o la explicación de su obra. La razón puede ser simple.

Los modernistas nunca penetraron realmente la esencia de las palabras de Whitman. Estaban a enorme distancia de él; ellos todavía saboreaban la atmósfera equívoca de un exotismo aprendido en los simbolistas franceses, quienes, entre paréntesis, lo habian digerido hacía tiempo. La democracia, la revolución, las masas, la lucha por construir un mundo nuevo y saludable por encima de las cenizas del liberalismo decadente del siglo xix y la pestilencia del mal $d u$ siècle, no eran elementos para una poesía que se alimentaba de duquesas, Luises y alfombras orientales. Para Darío - hombre degenerado y débil, a quien las masas le disgustaban profundamente, que gozaba de la sociedad elegante y se enorgullecía de haberle besado la mano a un rey-, las palabras de Whitman, palabras de hombre, palabras 
del pueblo, eran demasiado sólidas. Nunca sintió la tremenda verdad que estaba escondida en Leaves of Grass; una verdad lo bastante dura para destruir un mundo y poner al pueblo en marcha para crear otro. Darío cantó a Whitman en un soneto mediocre que le acerca a Chocano a causa de su vaciedad.

Chocano imitó a Darío, pero su imitaciỏn se limitó a lo más externo. E1 lenguaje bíblico de Whitman a veces produce el efecto de una orquesta sinfónica entera; está siempre lleno de significado, aunque sólo se trate de enumeraciones en que las palabras adquieren esa individualidad que acaso poseían cuando el hombre empezaba a expresarse. Chocano, usando el mismo tono, suena vacío, ruidoso, grotesco. Whitman fué el poeta del pueblo en el sentido de que transformó al hombre común en un gigante del futuro. Chocano quiso cantar a los hombres fuertes y apenas si cantó a todos los tiranuelos que halló en sus vagabundeos por Hispanoamérica. ${ }^{13}$

Como en tantos otros casos, los modernistas probaron de nuevo su superficialidad cuando hablaban sobre Whitman con infantil entusiasmo, le imitaban su apariencia y repetían sus palabras sin conseguir jamás entenderle. Tan sutiles fueron los métodos usados por los modernistas para aproximarse a los grandes poetas que deberían llegar a ser sus maestros, que aún hoy los críticos, cuando tratan de penetrar sus misterios, se exponen a conflictos de opiniones como el que se verá a continuación.

Antonio Aita, en su artículo Las corrientes literarias de América, ${ }^{14}$ refiriéndose a la Argentina, declara:

$Y$ nos acercamos al momento de mayor significación en nuestras letras. Aquél que congrega en el Ateneo, en torno a Darío, a la juventud impaciente... Ninguno, absolutamente ninguno, sentía por los escritores ibéricos la atracción que ejercian los franceses y algún poeta de habla inglesa como Whitman o Poe...

De tal modo que Whitman impulsó a los modernistas en la Argentina, pero atención a lo que sigue: E. Suárez Calimano, en otro artículo, ${ }^{15}$ distingue dos tendencias en la reacción contra el modernismo:

... de aquélla nació, bajo la influencia de Francis Jammes y Walt Whitman, la pléyade de poetas que abominaron del mundo modernista ... 
Es la voz de Whitman lo que está presente a través de todo el movimiento modernista, no su espíritu. Sus palabras se transforman en consignas, aun sus temas son parafraseados; pero su concepción del hombre y de la vida no sería asimilada sino hasta después de la primera guerra europea, cuando un pequeño grupo de poetas abandonó el surrealismo como pasatiempo y le colocó al servicio de la revolución socialista.

En mi opinión, Pablo de Rokha es el mejor representante de esta tendencia en Hispanoamérica; posee profundidad de pensamiento y una visión de gran alcance; su lenguaje es tan poderoso como el de Whitman ; es asombrosamente original, casi una creación propia del poeta $y$, sin embargo, tan típicamente chileno, que se podría tomar como una milagrosa floración del slang del roto; usa el mismo tono bíblico de Leaves of Grass, la misma corriente desenfrenada de substantivos y adjetivos, arrasando con los convencionalismos de la gramática. Su poesía es un vehemente clamor de protesta, un golpe decisivo contra los oligarcas, un himno épico de amor al pueblo; su pensamiento mismo está injertado en la intención social. Espíritu, lenguaje, actitud hacia la vida y genio - el elemento misterioso- hermanan a Whitman y a de Rokha en la poesía de América.

\section{Critica de Whitman}

Me ha parecido indispensable insertar aquí algunos comentarios sobre cinco de los artículos mencionados en la bibliografía; siendo sus autores figuras eminentes en el panorama literario de nuestra América, en cierto modo reflejan la posición oficial de Whitman entre nosotros.

José Martí escribió un artículo que por varias razones ha permanecido entre lo mejor que se ha escrito sobre el poeta norteamericano; no creo que Martí intentara hacer una interpretación definitiva; no es sino una carta dirigida al director de un periódico y concebida en términos entusiastas y afectuosos. Martí asistió a una ceremonia en Nueva York, en la cual Whitman lamentó la muerte de Lincoln; la impresión recibida por el patriota cubano fué profunda; su carta es casi una paráfrasis en prosa de todo lo que Whitman dijo en aquella ocasión y de muchas de las ideas contenidas en Leaves of Grass; ella revela que Martí leyó a Whitman con amor y comprensión y que encontró en él mucho de sus propios sueños. Esta carta 
o artículo de Martí es, a mi juicio, la interpretación de Whitman más sentida que haya escrito un hispanoamericano. ${ }^{16}$

A. Torres-Rioseco, uno de los pioneers del hispanoamericanismo en los Estados Unidos, escribió hace años una crítica de Whitman. Es un librito destinado a introducir "conscientemente" la obra del "gran yanqui" en Hispanoamérica. Hay una primera parte dedicada al Hombre, un vago relato de su vida. La segunda parte trata del Poeta; en ella el autor discute el verso de Whitman, su forma y su significación; nos habla de la antipatía de Whitman por las escuelas literarias $\mathrm{y}$, finalmente, presenta su mensaje democrático al nuevo mundo. E1 libro, que fué escrito en 1922, está lejos del sereno escepticismo que deja traslucir la última obra del gran crítico chileno; es más bien el testimonio de un poeta joven: encendido de exaltación. E1 relato de la vida de Whitman y el análisis de su poesía son frecuentemente interrumpidos por gritos de admiración y por los irritados ataques del crítico contra los "falsos poetas". Pero tal vez a causa de ser un libro joven, el lector encuentra en él algo de la misteriosa vitalidad y alegría de vivir que caracterizaron a Whitman; el libro nos proporciona una rápida imagen del universo revolucionario del poeta. La tercera parte se compone de traducciones de Leaves of Grass. ${ }^{17}$

Luis Alberto Sánchez, el distinguido crítico peruano, ha escrito en su Panorama de la literatura actual ${ }^{18}$ algunas páginas de gran interés para el especialista en Whitman. En su capítulo sobre Dandismo y Futurismo escoge a Oscar Wilde como representante del primero, y al señalar su romanticismo individualista ofrece como contraste "el espíritu de cooperación, de disciplina, de fábrica", y a Whitman como representante de este nuevo espíritu. "En tanto que Kipling - continúa Sánchez- será el cantor de la expansión territorial y económica, del imperialismo moderno, y Wilde el nuncio de una delicuescencia indetenible, Walt Whitman augurará la industria y la rudeza indispensable para el nuevo estado del mundo." Luego nos plantea una curiosa comparación:

Wilde, a pesar de todo, era menos inmoral que Queensberry y que Whitman. Wilde era sociable, esteta, gentleman, extramoral, confortable, amable, humorista, individualista, optimista. Whitman fué insociable, pero sociable, activo, grosero, laborioso, huraño, afirmativo, profético, tumultuoso, optimista, amoral. Coincidirán en el optimismo, en su riña con la moral ambiente y en haber sido puestos en el Index. Los hijos de los que ayer 
prohibieron Leaves of grass, son los que hoy fundan sociedades whitmanianas... Pero a Whitman lo combaten porque materializa la vida y le da un carácter pragmático por antonomasia. El es quien define el amor como "el poema de los senos y las caderas en acción". . Whitman es rudo, trabajador, hombre de fábrica, de canto al cuerpo eléctrico, y a veces, cuando se siente lírico, lanzará un marcial poema: "Oh captain, my captain", disfrazador de una elegía. Wilde representa el confort inglés, mientras que Whitman es el amanecer del industrialismo yanqui. Whitman es por eso profético hasta en sus barbas, y Wilde mondado hasta en sus mejillas rasuradas y gordiflonas $y$ en su estilo equívoco y deslumbrante. (pp. 61-62.)

Pero esto no es todo; Whitman también puede ser comparado con Marinetti, el maestro del futurismo - p. 64- y de la comparación resulta que los dos son tan diferentes, como un profeta y un clown. Sánchez también constata la influencia de Whitman en la poesia hispanoamericana en su Breve historia de la literatura americana. ${ }^{19}$

Interesantes son las opiniones del poeta argentino Luis Franco, quien, además de varios libros de versos, ha hecho un estudio sobre el autor de Leaves of Grass cuya introducción es el artículo que ahora vamos a comentar. ${ }^{20}$

En su artículo, ${ }^{21}$ Franco trata de penetrar las implicaciones politicas y filosóficas de Leaves of Grass. Su método es casi dialéctico, pero la poesía no ha sido subestimada. Sólo señalaré tres de sus observaciones. Franco explica cómo Whitman descubre al hombre auténtico y cuáles son las cualidades que le caracterizan. Luego se extiende en consideraciones sobre el individualismo de Whitman que se resuelve, a su juicio, en una especie de egoísmo altruísta. Sólo en este sentido, Whitman es el poeta de la democracia. Finalmente, Franco cree que Whitman descubrió la verdad sobre la democracia norteamericana: la vieja explotación tiene nuevos métodos y otro nombre; el capitalismo reduce al hombre moderno al mismo régimen de esclavitud de la edad media y de los tiempos antiguos. Pero Whitman vió en la clase trabajadora el mejor material humano, y esta intuición tiene su corolario evidente en la afirmación marxista de que no puede haber democracia sin socialismo. El poder material debe estar al servicio del hombre para ayudarle a realizar su liberación. El desarrollo de la personalidad humana necesita un proceso de socialización y destrucción de todas las discrepancias resultantes de nuestras obligaciones colectivas y nuestro ser individual. 
Más periodístico que el de Franco es el artículo de José Gabriel, que conmemora el quincuagésimo aniversario de la muerte de Whitman. ${ }^{22}$ En él se nos dice que hace falta una crítica seria sobre el verdadero Whitman; a juicio de Gabriel, el público de Hispanoamérica no ha conocido todavía la personalidad del poeta yanqui en toda su amplitud. Está claro que lo desagradable para el autor de tal artículo es el hecho de que hasta ahora se haya exaltado sólo el Whitman revolucionario o "propagandista". Recuerda la traducción de Vasseur "que conocimos hace treinta años" y agrega: "en el desconocimiento del auténtico Whitman continuamos hoy, a pesar de las traducciones parciales, ya más atentas, de Torres-Rioseco, de Montenegro, de León Felipe ... El ensayo crítico-biográfico dé nuestro buen Luis Franco (que sin embargo conoce y parafrasea bien las Leaves) restablece poco más o menos al poeta propagandista de la Biblioteca Blanca, $y$ por eso no ha cundido. Con todo, esas mismas nuevas traducciones y exaltaciones, y aun el ensayo de Franco, revelan que queremos volver a Whitman, que queremos, mejor dicho, acercarnos a él por primera vez." Para Gabriel, Whitman fué el poeta de un nuevo mundo, un mundo donde ni siquiera el pecado está ausente, pero donde todo contribuía a la liberación de la humanidad por medio del bienestar y del amor o, como él prefirió decir, por medio de la camaradería.

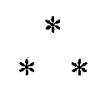

En cuanto a las traducciones de Whitman en Hispanoamérica, hay que reconocer que han sido parciales y bastante libres. En la bibliografía que completa este trabajo menciono sólo las que considero más fieles y, al mismo tiempo, de mayor significación artística.

La crítica sobre Whitman se ha desarrollado en los últimos años, a pesar de la aparente apatía de nuestras revistas literarias. ${ }^{23}$ Estoy seguro, sin embargo, de que cuando ellas empiecen a recoger los resultados de la actual política de intercambio cultural entre las Américas, los estudios sobre la personalidad y obra de Whitman serán más numerosos.

\author{
Fernando Alegría, \\ University of California.
}




\section{BIBLIOGRAFIA}

1) Capítulos y referencias en libros

Aldunate Phillips, Arturo.-Estados Unidos, gran aventura del hombre. Santiago, Chile. Ed. Nascimento, 1943.

Armas y CÁRdenAs, José DE.-Histotia y literatuta. Habana, Ed. J. Montero, 1915.

DARfo, RUBÉN.-Autobiografía. Obras Completas, Vol. XV. Madrid, Ed. Mundo Latino, 1917.

—. Prosas profanas. Obras Completas, Vol. II. Madrid, Ed. Mundo Latino, 1917.

DAvalos, BALBino.-Los grandes poetas notteameticanos. México, Tip. de la Oficina Impresora del Timbre, 1901.

Donoso, ARMAndo.-La senda clata. Buenos Aires, Ed. "Buenos Aires", 1919.

Gómez CARrillo, E.-Literatura extranjera. París, Ed. Garnier Hnos., 1895.

MARINELlo, JUAN.-Litetatuta hispanoameticana - Hombres - Meditaciones. México, Ed. de la Universidad Nacional de México, 1937.

Martí, José.-Notteameticanos. Obras Completas, Vol. XV (1). Habana, Ed. Trópico, 1939.

Nichols, MAdAline y BURK KInNatrd, Lucfa.-Bibliografía hispánica, Nosottos (Artículos sobre literatura hispanoamericana), 1937.

-2.. A bibliography of articles in Nosotros; general literary criticism, exclusive of Hispanic American literature, 1935.

RAMos, J. ANTONIO.-Panorama de la literatuta norteamericana. (1600. 1935.) México, Ed. Botas, 1935.

SÁNCHEZ, L. A.-Panorama de la literatuta actual. Santiago, Chile, Ed. Erci11a, 2a ed., 1935.

- Breve historia de la literatura americana. Santiago, Chile, Universidad de Chile, 1934.

SILva CASTRO, R.-Retratos literatios. Santiago, Chile, Ed. Ercilla, 1932.

- Obras desconocidas de Rubén Dario. Santiago, Universidad de Chile, 1934.

Torres Pinzón, C. A'--Prosas y esbozos. Bogotá, Tip. Minerva, 1917.

TORRes-RIoseco, A.-Rubén Darío. Cambridge, Mass., Harvard University Press, 1931. 
ZUM Felde, A.-Proceso intelectual del Uruguay. Montevideo, Imp. Nacional Colorada, 1930.

2) Artículos sobre Walt Whitman en revistas

AITA, ANTONIO.- "Las corrientes literarias de América", Nosotros, NovDic., 1930.

ENGLEKIRK, JOHN E.- "Notes on Whitman in Spanish America", Hispanic Review. Vol. VI, 1938, págs. 133-138.

FRANCO, LUIS.—"Vida politica de Walt Whitman", Repertorio Americano, núm. 963, 26 de junio, 1943.

—. "Walt Whitman el pioneer", Babel, Santiago, Chile, Sept.-Oct., 1940.

GABRIEL, JOSÉ.—“El cincuentenario del tránsito de Walt Whitman", Atgentina Libre, Buenos Aires, 26 de marzo, 1942.

INDO, CLAUDIO.- “Sobre algunos poetas norteamericanos", Atenea, núm. 190, abril, 1941, págs. 85-118.

Meza Fuentes, R.- “La poesía de José Santos Chocano", Nosotros, Ābr.Dic., 1934, págs. 306-310.

SUÁRez CALIMANo, E.- "La literatura hispanoamericana", Nosottos, agosto, 1927 .

UMPHREY, GEORGE W.-“Chocano y Whitman", Cultura Venezolana, 1922.

VARELA, LorenZo.- “Canto a mí mismo” de Walt Whitman (Crítica de la traducción de León Felipe), Argentina Libre, 12 de marzo, 1942.

\section{3) Libros y folletos sobre Walt Whitman}

Cameron, Rogers.-Vida de Walt Whitman. La Plata, Argentina, Ed. Cayetano Calomino, 1942.

Montolicl, C.-Walt Whitman, el hombte y su obta. Buenos Aires, Ed. Poseidon, 1943.

Soto, JuAN B.-Rubén Datio y Walt Whitman. Puerto Rico, 1917.-(Mencionado por J. E. Englekitk.)

TORRES-RIoseCO, A.-Walt Whitman. San José de Costa Rica, Ed. J. García Monge, 1922.

TURINA, PEPITA.—Walt Whitman, cotidiano y eterno. Santiago, Chile, Prensas de la Universidad de Chile, 1943. 
4) Traducciones y antologías

Aguilera, Francisco.-Pioneet, Oh Pioneer. Gentes de Amética. Distribuido por Panamerican Union.

FELIPE, LEÓN.-Prólogo y traducción, epilogo de Guillermo de Torre. Canto a mi mismo, Walt Whitman. Buenos Aires, Ed. Losada, S. A., 1941.

GABRIEL, JosÉ.-La época modetna, Walt Whitman. Argentina Libre, Buenos Aires, 26 de marzo, 1942.

Montenegro; ERnesto.-_"Oh capitán! Mi capitán!" Babel, Santiago, Chile, Sept.-Oct., 1940.

MORAles, ERnesto.-Antología de poetas americanos. Buenos Aires, Ed. Santiago Rueda, 1941.

Romagosa, Carlos.-Joyas poéticas ameticanas. (Mencionado por Ernesto Morales.-Los poemas de Whitman aparecen en inglés.)

Soto, FaUsto.- Traducción aún no publicada de gran parte de la obra de Walt Whitman.

Vasseur, Armando.-Walt Whitman, Poemas. Montevideo. E. Claudio García y Cía., 1939. (Traducción y prólogo de A. Vasseur, con un juicio de $A$. Guerra.)

$$
\text { F. A. }
$$

\section{NOTAS}

1 Este artículo, destinado a formar parte de un Handbook sobre Whitman cuyo editor es el profesor Gay W. Allen, fué escrito especialmente con el propósito de informar al público norteamericano.

2 Este artículo se publicó en El Pattido Libetal, abril 1887, y luego se reprodujo en Notteamericanos, Habana, 1909, Obras Litetarias de José Martí, vol. 8, págs. 311-328.

3 Madrid, 1917, Ed. Mundo Latino, Obras Completas, vol. 4, pág. 217.

4 Walt Whitman, Poemas, 1939, Ed. García, Montevideo. Juzgando por la difusión alcanzada por esta obra, podtíamos considerar a Vasseur como el verdadero introductor de Whitman en Hispanoamérica.

5 La poesía de Neruda experimentó una transformación decisiva a consecuencia de la guerra civil española. Un simbolista dudoso a los veinte años, un profundo innovador en su obra maestra Residencia en la tierta, surge de la guerra civil con un libro, España en el corazón, que indudablemente representa el mayor esfuerzo de toda su carrera. Con el mecanismo de un surrealismo quintaesenciado $y$ un sincero amor por el pueblo y las realizaciones de la revolución proletaria, Neruda se dirige a las masas. Por primera vez trata de ser consciente- 
mente objetivo. Abre sus ojos a la realidad inmediata y en vez de sombras reproduce los verdaderos objetos. Después de años de escritura automática y de residir en un vórtice, vuelve al pueblo con un claro mensaje y una voz incendiaria. E1 resultado: sus compañeros surrealistas gritan que Neruda está acabado; el arte proletario le recibe como a un hijo predilecto. Los críticos no pueden menos de pensar que Whitman tiene una voz más en el Coro que engrandece su texto.

6 Durante años considerado como uno de los más distinguidos discípulos de Whitman en Sudamérica. Zum Felde, el crítico uruguayo autor de Proceso intelectual del Utuguay (1930, Imp. Nacional Colorada, Montevideo), caracteriza la poesía de Sabat Ercasty de la siguiente manera: "No sólo por su lirismo cósmico y vital, sino por su manera caudalosa y extensiva, la poesía de Sabat ha sido comparada a la de Whitman, queriendo así sus amigos justificar esa carencia de síntesis formal de que adolece. Sólo cabría observar que esa característica de Whitman no es precisamente una de sus virtudes, sino uno de sus defectos; pero en Whitman está contrapesado casi siempre (sic) por una densa sustantividad del contenido; en Sabat, el contenido, casi siempre mental y abstracto, tiende a la inflazón verbalista." Ibidem., pág. 168.

7 Distinguido poeta argentino contemporáneo, autor de un poema a Whitman que aparece en Antología poética argentina, por J. L. Borges, S. Ocampo, A. Bioy Casares, 1941, Buenos Aires, Ed. Sudamericana, pág. 113.

8 Un joven poeta argentino canta del siguiente modo al aniversario nacional de su patria: "Soy yo, que vengo cargado de mayúsculas, - de signos de admiración y de interrogación, - yo, que vengo afirmando, - delante de los vientos, - la insólita importancia de ser hombre..." "... sobre montañas de cemento, cuero, cereales, leche, lana, maderas, herrerias, quesos, cebollas, cementerios, pescados, muelles, rosas, lunas... ferry-boats..." (Tomado de Himno a la libre Argentina. González Tuñón, mayo 1942.)

9 Vol. XV de sus Obras Completas, Ed. Mundo Latino, Madrid, 1917.

10 Vol. II, Obtas Completas, Ed. Mundo Latino, Madrid, 1917.

11 Obras desconocidas de Rubén Datío, Santiago, Prensas de la Universidad de Chile, 1934.

12 Rubén Darío, Cambridge, Massachusetts, Harvard University Press, 1931, pág. 33 .

13 Un crítico norteamericano, G. W. Umphrey, y otro chileno, R. Meza F, han estudiado a Chocano en relación con Whitman. El artículo de Meza apareció en Nosotros, Buenos Aires, abril-diciembre 1934, págs. 306-310.

14 Nosotros, noviembre-diciembre 1930, pp, 240-241.

15 La literatuta hispanoamericana, en Nosottos, agosto 1927, pág. 298.

16 He aquí el sumario del artículo de Martí: Fiesta literaria en New York-Vejez patriarcal de Whitman-Su elogio a Lincoln y el canto a su 
muerte-Carácter extraordinario de la poesía y lenguaje de Whitman-Novedad absoluta de su obra poética-Su filosofía, su adoración del cuerpo humano, su felicidad, su métoco poético-La poesía en los pueblos libres-Sentido religioso de la libertad-Desnudeces y profundidad del libro prohibido de Whitman.

17 Poetas notteamericanos, Walt Whitman, A. Tortes-Rioseco, San José de Costa Rica, C. A., 1922, Ed. J. García Monge. Seis de las traducciones que aparecen en la tercera parte del libro han sido incluidas en la Antología de poetas ameticanos, Ernesto Morales, Buenos Äires, Santiago Rueda, Editor, 1941.

18 Santiago, Ercilla, 1935, 2ª edición.

19 Santiago, Ercilla, 1940, 2a edición; ver págs. 555 y 557 especialmente.

20 No tengo, desgraciadamente, evidencia sobre la publicación de este ensayo, excepto una referencia en un artículo de J. Gabriel al cual nos referiremos más adelante.

21 "Walt Whitman, el pioneer", en Babel, Santiago de Chile, Sept.Oct., 1940.

22 El cincuentenario del ttánsito de Walt Whitman, en Argentina Libre, 26 de marzo 1942.

23 En mis investigaciones he tenido ocasión de hojear varias colecciones de revistas, algunas tan prestigiosas como Atenea, Sut, Nosottos, y de hallar, para sorpresa mía, apenas ligeras referencias a Whitman. 